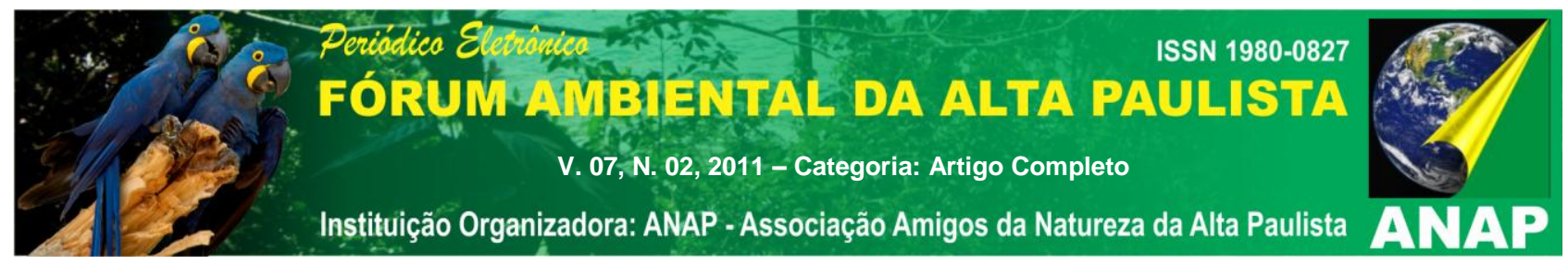

\title{
UTILIZAÇÃO DE DADOS E TÉCNICAS DE SENSORIAMENTO REMOTO NO MONITORAMENTO DA INFESTAÇÃO POR PLANTAS AQUÁTICAS EM RESERVATÓRIO DE HIDRELÉTRICA
}

\author{
Carina Regina de Macedo ${ }^{1}$ \\ Maria de Lourdes Bueno Trindade Galo²
}

\begin{abstract}
RESUMO: Como um efeito do desequilíbrio causado pelo represamento dos rios e pela poluição, é observado uma crescente infestação por plantas aquáticas em reservatórios destinados à geração de energia elétrica. Esses locais têm sido utilizados também para inúmeras outras finalidades, além da geração de energia, isso inclui lazer, captação de água e navegação. Dessa maneira é importante avaliações periódicas desses corpos d'água, afim de verificar as condições determinantes de crescimento de algas, plantas e outros organismos. Nesse sentido, a tecnologia do Sensoriamento Remoto pode se constituir numa ferramenta valiosa para o mapeamento e monitoramento das propriedades ópticas da água, de modo a fornecer subsídios para o efetivo manejo desses ambientes aquáticos. Este trabalho tem como objetivo realizar o monitoramento da ocorrência de plantas aquáticas no Reservatório da Usina Hidrelétrica Salto Grande, localizada em Americana, SP, por meio de imagens multiespectrais tomadas por sensores instalados em satélites da série Landsat, em três anos consecutivos: 2008, 2009 e 2010. O procedimento metodológico adotado incluiu o registro das imagens e a classificação multiespectral das imagens de modo a mapear, a cada ano, a localização e extensão das áreas infestadas por plantas aquáticas.
\end{abstract}

Palavras-Chave: Sensoriamento Remoto; Imagens Multiespectrais; Monitoramento de Plantas Aquáticas em Reservatórios.

\section{1 - INTRODUÇÃO}

Os reservatórios destinados à geração de energia elétrica têm sido utilizados para inúmeras outras finalidades, incluindo lazer, captação de água e navegação, entre outras. Desse modo, avaliações periódicas dos constituintes e da qualidade da água são

\footnotetext{
1 Estudante de Eng. Ambiental, UNESP/FCT, Presidente Prudente. E-mail: carina regina@hotmail.com

${ }^{2}$ Engenheira Florestal, professora Auxiliar da UNESP/FCT, Presidente Prudente. E-mail: mlourdes@fct.unesp.br
} 


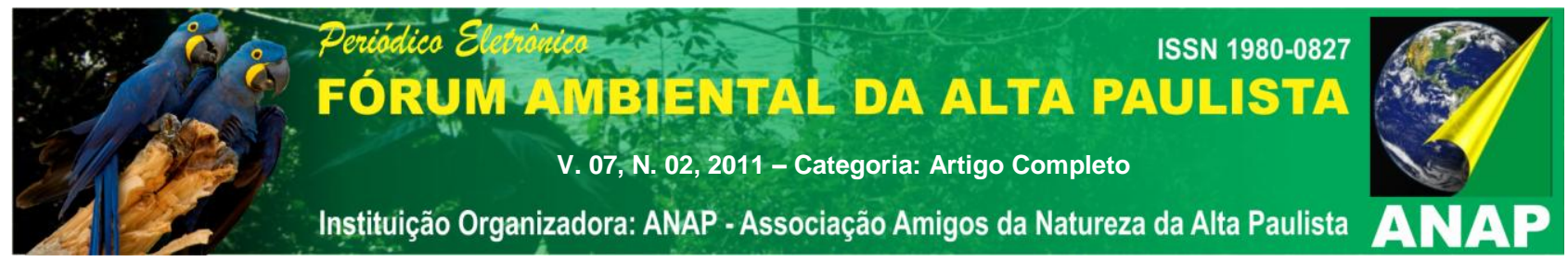

determinantes para avaliar o crescimento de algas, plantas e outros organismos e para que tais sistemas suportem múltiplos usos.

Nesse sentido, a tecnologia do Sensoriamento Remoto pode se constituir numa ferramenta valiosa para o monitoramento das propriedades ópticas da água, de modo a fornecer subsídios para o efetivo manejo dessas áreas, considerando a variedade de tipos e intensidade da intervenção antrópica identificados na área de influência dos reservatórios.

O reservatório da Usina Hidrelétrica de Salto Grande, localizada em Americana, SP, e gerenciado pela Companhia Paulista de Força e Luz (CPFL), tem apresentado consideráveis níveis de infestação por plantas aquáticas que, antes da implantação de um procedimento quase contínuo de remoção mecânica dessas plantas, causaram grandes prejuízos devido à interrupção no fornecimento de energia elétrica. O problema da remoção mecânica está no alto custo envolvido no processo, na necessidade de identificar áreas de descarte para as plantas removidas e dúvidas quanto à sua viabilidade financeira enquanto ferramenta de manejo.

Diante do exposto, considera-se que a localização dos bancos de macrófitas no contexto do corpo d'água, pode auxiliar no processo de adequar ou aprimorar um plano de manejo mais efetivo para o reservatório.

Foram utilizadas, para realizar este trabalho, imagens multiespectrais do sensor Thematic Mapper (TM) do satélite Landsat 5 e uma imagem $\mathrm{ETM}^{+}$(Enhancement Thematis Mapper Plus) do Landsat 7, abrangendo a área do reservatório da Usina Hidrelétrica de Salto Grande. A escolha dessa área de estudo deveu-se à disponibilidade de dados descritivos e imagens de satélite, mas também à grande quantidade de áreas infestadas por plantas aquáticas na represa.

\section{2- OBJETIVO}

Realizar o monitoramento da ocorrência de plantas aquáticas no Reservatório da UHE (Usina Hidrelétrica) de Salto Grande (Americana, SP), durante os anos de 2008, 2009 e 2010, através da classificação de imagens TM/Landsat 5. Esse procedimento tem 


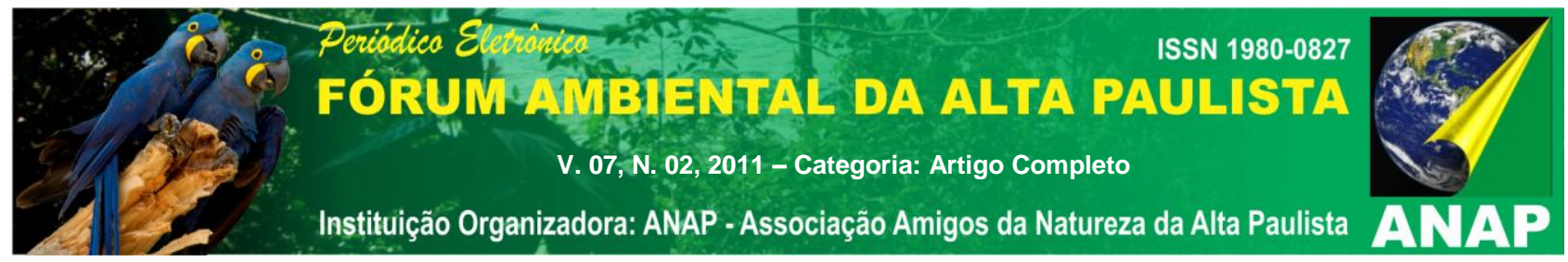

a finalidade de fornecer informações que possam contribuir para o manejo do reservatório, destinado à geração de energia elétrica.

\section{3- CONSIDERAÇÕES SOBRE A ABORDAGEM UTILIZADA}

\section{1 - Sensoriamento remoto da água}

A água líquida tem um comportamento espectral distinto dos demais alvos da superfície, pois a energia refletida por ela é consideravelmente menor que de outros alvos. Novo (1989, p.195) argumenta que "a água em seu estado líquido apresenta baixa reflectância entre $0,38 \mu \mathrm{m}$ e $0,70 \mu \mathrm{m}(\rho<0,1)$, absorvendo toda a radiação acima de 0,7 $\mu \mathrm{m} "$, como pode ser observado na Figura 3.

Diferente do solo e da vegetação, a maior parte do fluxo radiante incidente sobre a água não é refletido, mas absorvido ou transmitido. Nos comprimentos de onda do visível, pouca luz é absorvida, uma pequena quantidade é refletida e a maior parte é transmitida. Moreira (2001) destaca que a água no estado líquido absorve a radiação eletromagnética abaixo de 380nm e acima de 700nm e que, mesmo nessa faixa intermediária, a reflectância da água é relativamente pequena, ultrapassando pouco mais de 5\%. Especificamente para a água pura, a reflectância no espectro visível decresce de cerca de $5 \%$ no azul para menos de 1\% no infravermelho próximo, como pode ser visto na Figura 1 (NOVO et al., 1989). Desse modo, a forte absorção da radiação do infravermelho próximo e médio pela água resulta em um forte contraste entre a água e os limites de terra. 

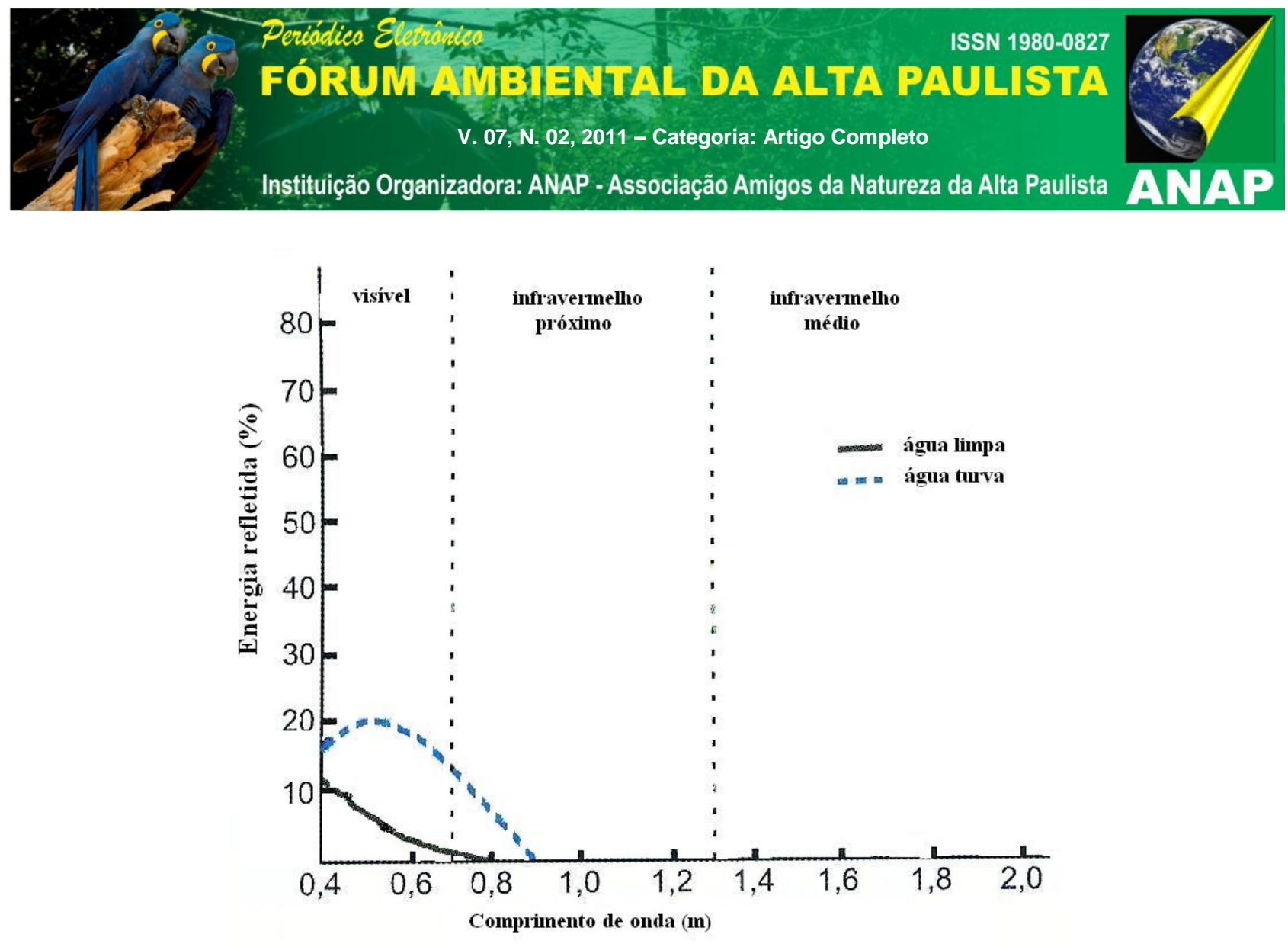

Figura 1 - Curva espectral da água.

Fonte: Adaptado de Florenzano, 2002.

Entretanto, quando na coluna d'água existem constituintes orgânicos e inorgânicos a resposta espectral da água se torna diferente, já que esses materiais produzem reflexão de superfície no infravermelho próximo e espalhamento volumétrico de superfície.

Os corpos d'água interiores e costeiros podem ter suas características de reflectância afetadas pelo transporte de sedimentos em suspensão. Jensen (2007, p.417) diz que "o sensoriamento remoto pode ser usado para monitorar as concentrações de sedimentos em suspensão nos corpos d'água". Isto geralmente requer a obtenção de medidas in situ de concentrações de sedimentos em suspensão e a correlação dessas medidas com dados de sensores remotos para obter uma relação quantitativa.

Para Trentin (2009, p. 26) "a faixa do espectro entre 700 - $900 \mathrm{~nm}$ (infravermelho próximo) é a mais adequada para estimar a concentração de sedimentos, uma vez que nesta faixa o aumento gradativo de sedimentos, aumenta de maneira uniforme a reflectância do corpo aquático". 

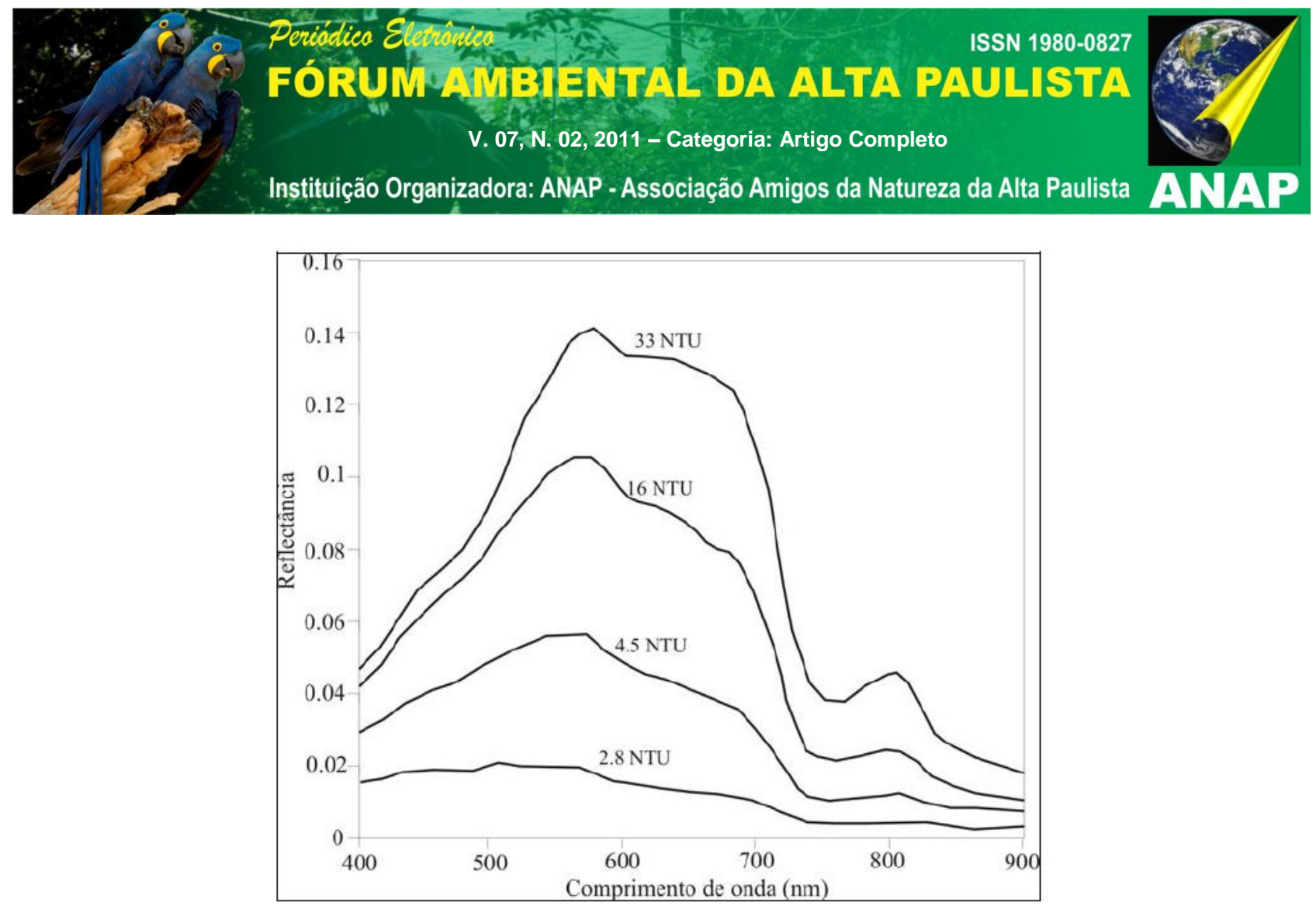

FIGURA 2 - Curvas espectrais com diferentes concentrações de sedimentos em suspensão em Unidade de Turbidez Nefelométrica (NTU).

FONTE: TRENTIN, 2009, p. 27.

A existência de clorofila na água provoca alterações em suas características espectrais. Para Jensen (2007, p.421), "quando a concentração de clorofila aumenta na coluna d'água, há um significativo decréscimo na quantidade relativa de energia refletida nos comprimentos de onda do azul e do vermelho, mas um aumento na reflectância do comprimento de onda do verde".

A matéria orgânica, por sua vez, também é responsável por uma mudança no coeficiente de absorção da água. "Estas substâncias absorvem muito pouco na região do vermelho, aumentando nas faixas de menor comprimento de onda, podendo se apresentar significante no azul e ultravioleta" (MOBLEY apud TRENTIN, 2009, p. 29).

\section{2- Classificação de Imagens de Sensoriamento Remoto}

"A classificação de imagens consiste no estabelecimento de um processo de decisão no qual um grupo de pixels é definido como pertencente a uma determinada classe. Neste sentido, os 


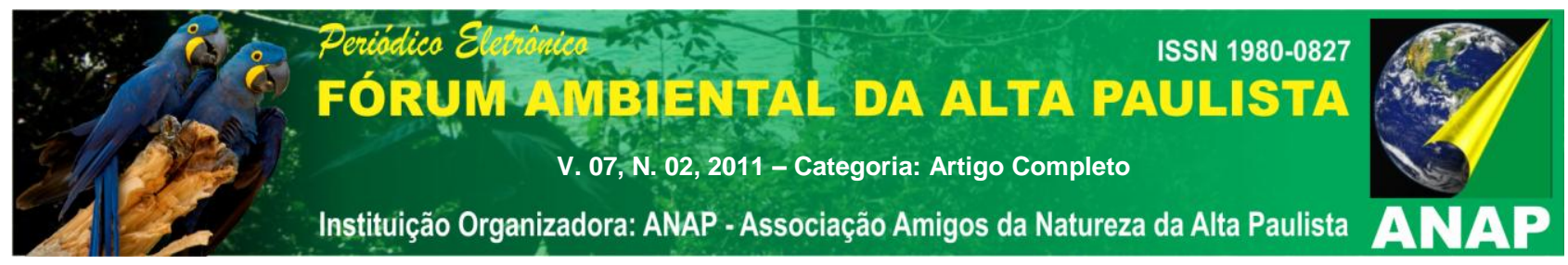

sistemas computacionais auxiliam o usuário na interpretação das imagens orbitais" (VENTURIERI e SANTOS, 1998, p.353).

Para Körting (2006, p.1) "os classificadores podem ser divididos em classificadores pixel a pixel e classificadores por regiões. Classificadores pixel a pixel utilizam apenas a informação espectral, isoladamente, de cada pixel para achar regiões homogêneas". Já os classificadores por regiões não utilizam apenas a informação espectral de cada pixel, mas também a informação espacial que envolve a relação de cada pixel com seus vizinhos. Assim, a classificação de uma imagem pode ser realizada com base no menor elemento de resolução da imagem (pixel). No entanto, como tais métodos consideram, individualmente, cada unidade radiométrica na análise, pixels que apresentem um comportamento radiométrico inconsistente podem ser classificados incorretamente (ou não ser classificados). De acordo com Venturieri \& Santos (1998), uma alternativa para resolver esse problema é a utilização de uma técnica de segmentação da imagem, a fim de agrupar os pixels que apresentam características radiométricas similares em termos tonais e texturais, formando regiões homogêneas e, então, classificar as regiões formadas.

INPE (2011) diz que os classificadores por regiões "procuram simular o comportamento de um foto-intérprete, reconhecendo áreas homogêneas de imagens, baseados nas propriedades espectrais e espaciais de imagens. A informação de borda é utilizada inicialmente para separar regiões e as propriedades espaciais e espectrais irão unir áreas com mesma textura". É importante destacar que a utilização desse tipo de classificador exige a prévia segmentação da imagem.

"Os métodos de classificação digital podem ser agrupados em função da presença ou não de uma fase de treinamento onde 0 analista interage com o computador" (VENTURIERI; SANTOS, 1998, p.353), definindo os métodos supervisionados ou nãosupervisionados

O tipo de classificação que não utiliza a fase de treinamento é chamado classificação não-supervisionada. Nesse método os pixels da imagem são associados a uma classe espectral sem um prévio conhecimento do nome ou da existência dessas classes. 


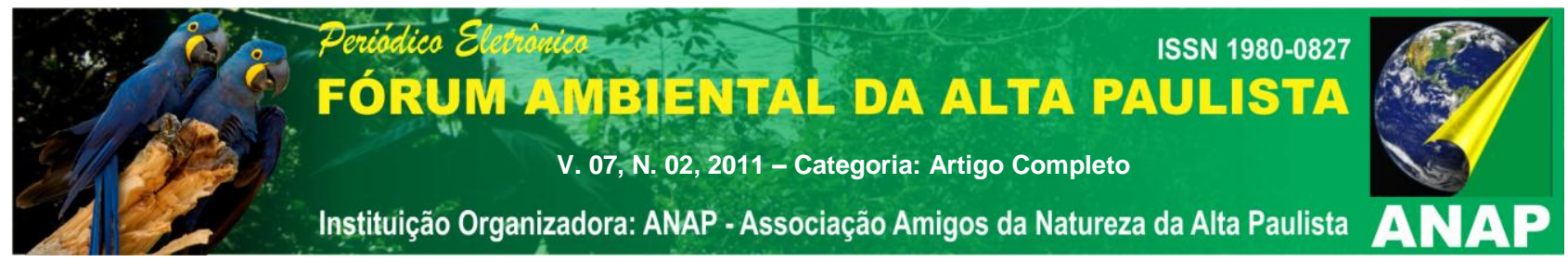

O outro método existente é a classificação supervisionada, que recebe esse nome pela interação entre o interprete humano e o sistema de análise. Nesse método há o conhecimento prévio da cena, o que permite a seleção de amostras de treinamento. A fase de treinamento do classificador consiste na seleção de amostras representativas, ou seja, que reflitam a variabilidade, de cada categoria dentro da área estudada. As amostras permitem estimar os parâmetros estatísticos de cada classe.

Neste trabalho foi utilizado um procedimento supervisionado de classificação de regiões denominado Bhattacharya. Definidas as regiões utilizando um processo de segmentação multiespectral da imagem, esse classificador utiliza as amostras de treinamento para estimar os parâmetros da função densidade de probabilidade normal para cada classe de informação e, em seguida, avalia, para cada região, a distância de Bhattacharya entre as classes, de modo que a classe que apresentar menor distância será atribuída à região avaliada. A equação a seguir mostra a formulação da distância de Bhattacharya:

$$
B\left(p_{i}, p_{j}\right)=\frac{1}{2}\left(m_{1}-m_{2}\right)^{T} \sum\left(m_{i}-m_{j}\right)+\frac{1}{2} \ln \frac{\left|\sum\left(m_{i}-m_{j}\right)\right|}{\left|\sum i\right|^{1 / 2}\left|\sum j\right|^{1 / 2}}
$$

Sendo que B = distância de Bhattacharya; pi e pj = pixels nas classes i e j; mi e mj = médias das classes i e j; T = matriz transposta; ln = logaritmo neperiano; e i e j = classes dentro do contexto.

\section{4 - MATERIAIS E METODOS}

\section{1 - Caracterização da Área de Estudo}

A Represa de Salto Grande está inserida na sub-bacia hidrográfica do rio Atibaia e segundo Cruz (2005, p. 106), pertence à bacia hidrográfica do rio Piracicaba. $O$ reservatório encontra-se entre os municípios de Nova Odessa, Paulínea e Americana, sendo que nesta última cidade localiza-se a maior parte de sua área. Essas cidades 


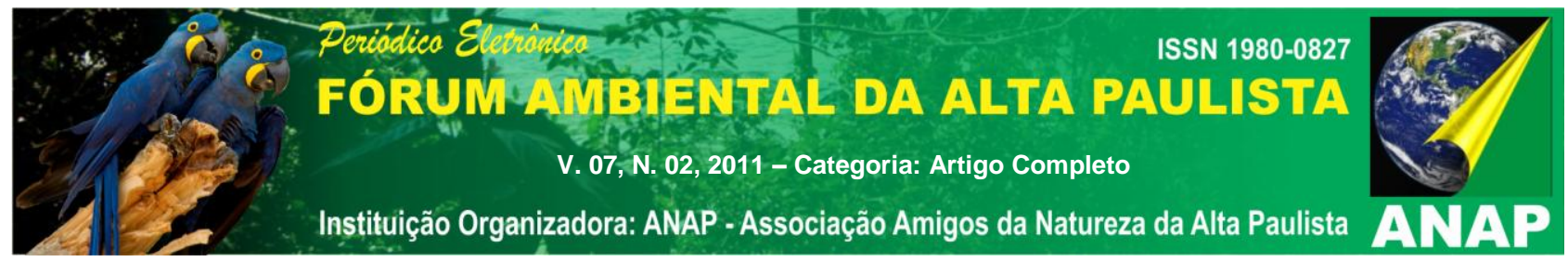

localizam-se na Região Metropolitana de Campinas, que é uma das regiões mais desenvolvida economicamente do Estado de São Paulo.

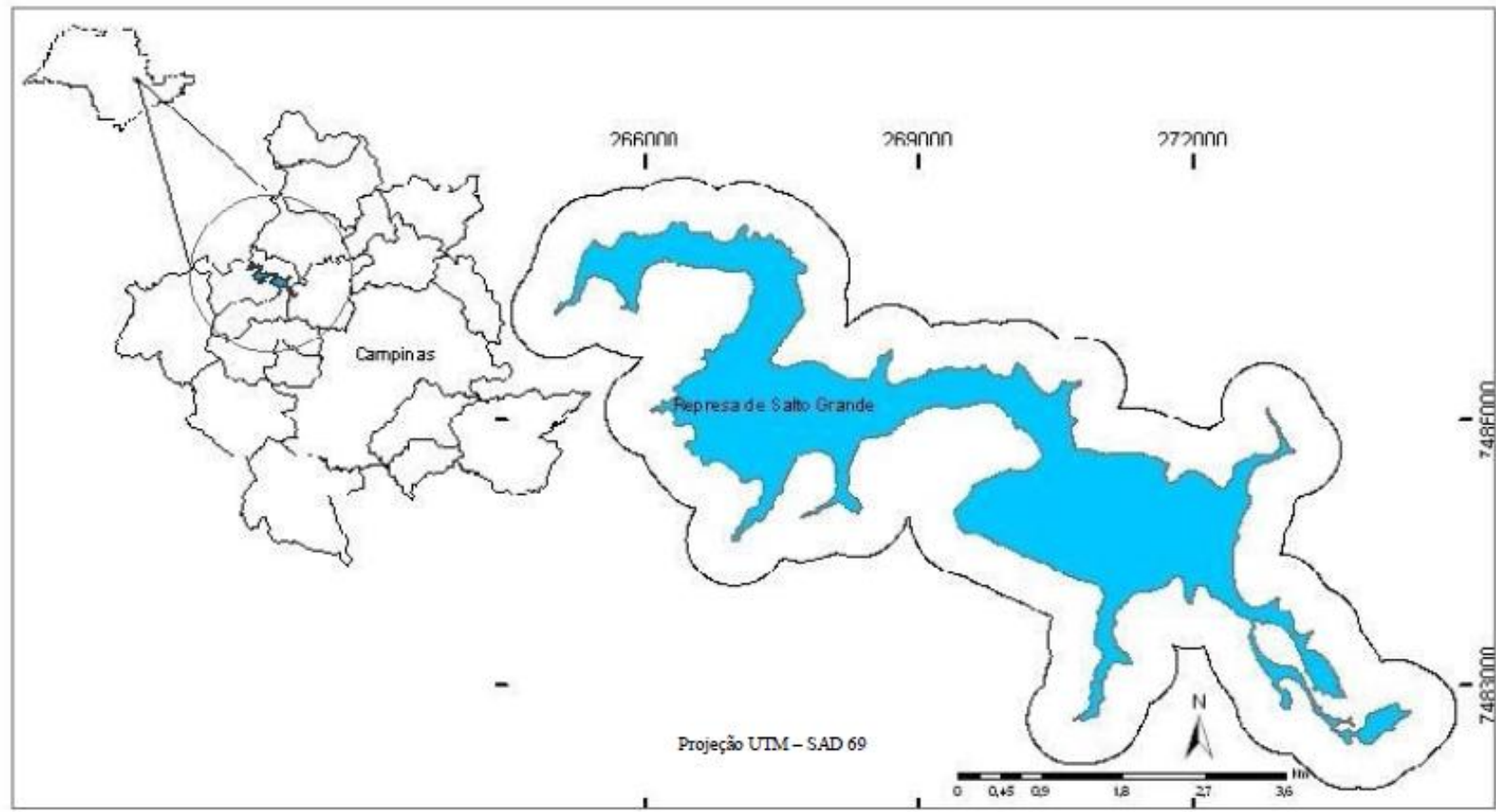

FIGURA 3 - Localização da Área de Estudo.

FONTE: CARVALHO et. al. , 2009, p.4.

Segundo a CPFL (2008), devido à falta de tratamento de esgoto, ao aumento da urbanização e da erosão do solo nas áreas no entorno da represa de Salto Grande, vem ocorrendo a eutrofização desse corpo d'água e a proliferação de plantas aquáticas. A infestação desse reservatório por plantas causa o impedimento ao uso de sua água, a proliferação de insetos e de animais peçonhentos e poluição visual, resultando na redução do valor das propriedades às margens da represa.

O crescimento exagerado de plantas aquáticas causa ainda impactos sobre a segurança da barragem do reservatório da UHE de Salto Grande e sobre a sua produção de energia, já que, de acordo com $\operatorname{Cruz}$ (2005, p.16), “o controle dessas infestações exige constante manutenção de grades de tomada de água das turbinas de hidrelétricas, o que muitas vezes interrompe a geração de energia". Pode-se listar também como problemas encontrados na UHE de Americana a dificuldade em navegar nesse reservatório e a impossibilidade do uso de sua água para banho. 


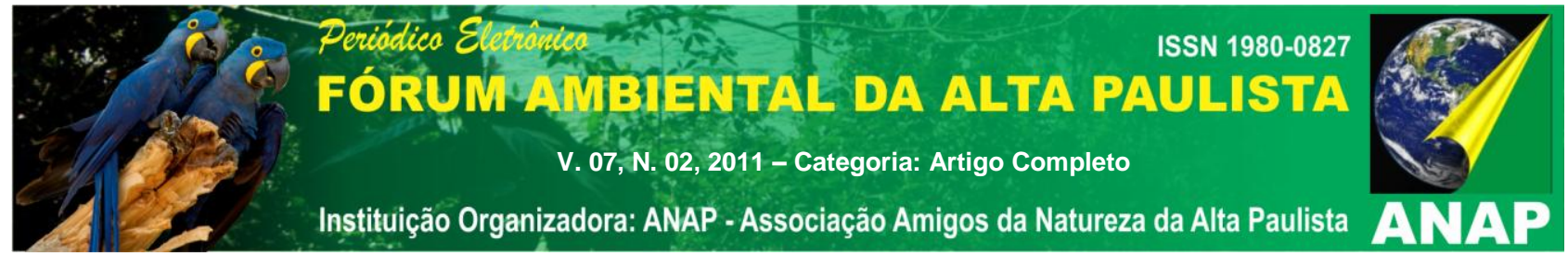

Segundo o levantamento desenvolvido por Cruz (2005) na UHE de Americana, as espécies de plantas aquáticas encontradas nessa região foram populações mistas de braquiária e aguapé e de braquiária, taboa e aguapé. Esses dados foram coletados em cinco pontos diferentes do reservatório em julho de 2004.

\section{2- Dados multiespectrais e descritivos utilizados}

Para realizar esse estudo foram utilizadas três cenas tomadas pelo sensor TM/LANDSAT 5 e uma pelo sensor $\mathrm{ETM}^{+} /$Landsat 7 , todas elas abrangendo o município de Americana e outras regiões próximas. A imagem $\mathrm{ETM}^{+} /$Landsat 7 foi utilizada como referência para o registro das imagens TM/Landsat 5 . Todas as imagens foram obtidas mediante download no site do INPE - Instituto Nacional de Pesquisas Espaciais (www.dgi.inpe.br).

QUADRO 1 - Caracterização das cenas utilizadas na pesquisa.

\begin{tabular}{|c|c|c|c|c|c|}
\hline & $\begin{array}{c}\text { Órbita/ } \\
\text { ponto }\end{array}$ & $\begin{array}{c}\text { Data da } \\
\text { imagem }\end{array}$ & $\begin{array}{c}\text { Bandas } \\
\text { espectrais }\end{array}$ & $\begin{array}{c}\text { Elevação } \\
\text { solar }\end{array}$ & $\begin{array}{c}\text { Azimute } \\
\text { solar }\end{array}$ \\
\hline Landsat5/TM(5) & $220 / 76$ & $08 / 07 / 2008$ & $\begin{array}{c}\text { TM1, TM2, } \\
\text { TM3, TM4, } \\
\text { TM5 }\end{array}$ & 33.478 & 38.7227 \\
\hline Landsat5/TM(6) & $220 / 76$ & $28 / 08 / 2009$ & $\begin{array}{c}\text { TM1, TM2, } \\
\text { TM3, TM4, } \\
\text { TM5 }\end{array}$ & 44.0087 & 48.0855 \\
\hline Landsat5/TM(7) & $220 / 76$ & $31 / 08 / 2010$ & $\begin{array}{c}\text { TM1, TM2, } \\
\text { TM3, TM4, } \\
\text { TM5 }\end{array}$ & 45.0062 & 48.6236 \\
\hline 8) & & & $\begin{array}{c}\text { TM1, TM2, } \\
\text { TM3, TM4, } \\
\text { TM5 }\end{array}$ & 45.2071 & 49.7356 \\
\hline
\end{tabular}




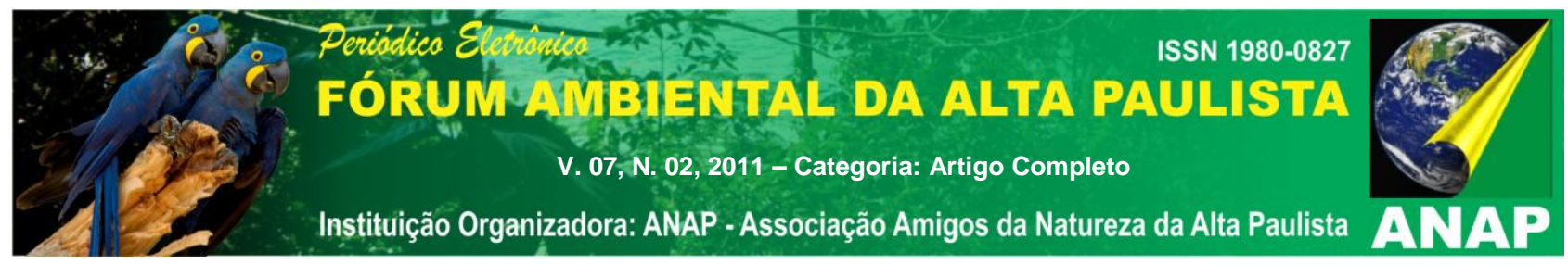

O sistema imageador Thematic Mapper, operando a bordo do Landsat 5, possui sete bandas espectrais. Seis dessas Bandas (TM1, TM2, TM3, TM4, TM5, TM7) apresentam resolução espacial de 30 metros no terreno, enquanto que a banda TM6, que capta a radiação termal, tem uma resolução espacial de 120 metros. As bandas espectrais correspondem aos seguintes intervalos de comprimento de onda: região do azul com comprimentos de onda entre 0,45 e 0,52 $\mu \mathrm{m}$ (TM1), região do verde com comprimentos entre 0,52 e 0,6 $\mu \mathrm{m}$ (TM2), região do vermelho entre 0,63 e 0,69 $\mu \mathrm{m}$ (TM3), região do infravermelho próximo entre 0,76 e 0,9 $\mu \mathrm{m}$ (TM4), infravermelho médio entre 1,55 e 1,75 $\mu \mathrm{m}$ (TM5), infravermelho termal entre 10,40 e 12,50 $\mu \mathrm{m}$ (TM6) e infravermelho médio entre 2,08 e 2,35 $\mu \mathrm{m}$.

O sensor $\mathrm{ETM}^{+}$, que está presente no satélite Landsat 7 , mostra-se como um aprimoramento do TM, apresentando as seis bandas ópticas com resolução espacial de 30 metros no terreno, a termal com resolução espacial de 60 metros e, adicionalmente, uma banda pancromática com resolução espacial de 15 metros.

O processamento e análise digital dos dados multiespectrais foi realizado utilizando - software gratuito Spring (Sistema de Processamento de Informações Georreferenciadas). Segundo Santos et. al. (2010, p.10), "esse software é um banco de dados geográfico, desenvolvido pelo INPE (Instituto Nacional de Pesquisas Espaciais)".

\section{3- Processamento e análise das imagens multiespectrais}

O fluxograma abaixo sintetiza os procedimentos adotados no presente trabalho.

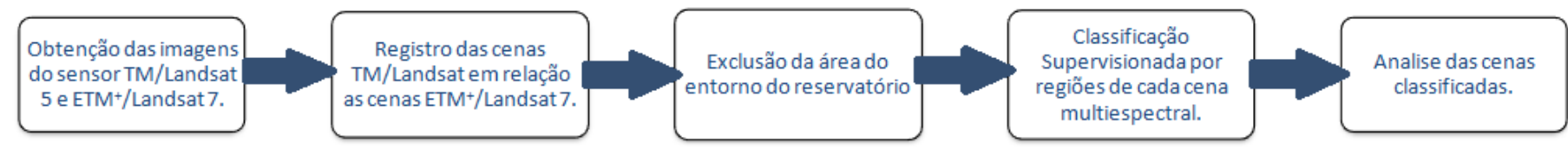

Inicialmente, as imagens TM/Landsat 5 foram registradas em relação a imagem $\mathrm{ETM}^{+} /$Landsat 7. O Registro de Imagens é o processo que faz com que pontos correspondentes em duas imagens distintas tornem-se espacialmente coincidentes. Esse processo envolve a seleção de pontos homólogos em uma imagem de referência $\left(\mathrm{ETM}^{+}\right)$ 


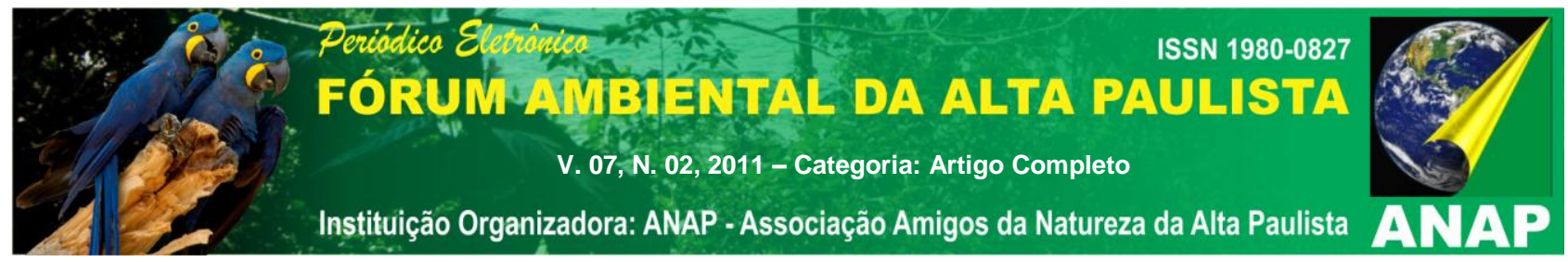

e na imagem a ser registrada e a aplicação de uma função que fará uma transformação geométrica na imagem de interesse, de modo que as feições coincidentes tenham as mesmas coordenadas espaciais da imagem de referência. O procedimento foi aplicado individualmente a cada data de aquisição de imagem TM.

Numa etapa posterior, a região do entorno da represa foi excluída, de forma que a detecção das variações espectrais no corpo d'água fosse facilitada. Esse procedimento, que consiste em criar uma máscara delimitando o corpo d'água e aplicá-la a cada banda de cada imagem multitemporal, é necessário já que muitos alvos do entorno do reservatório se confundem com plantas aquáticas.

Para a posterior classificação das imagens, foi necessário definir previamente as classes de interesse. Nesse caso, a caracterização foi bastante simples, já que se trata da identificação (no contexto do corpo d'água) das áreas infestadas por plantas aquáticas. As duas classes de interesse especificadas foram: plantas aquáticas e água. O Quadro 2, mostrado a seguir, mostra as características de cada uma dessas classes na imagem. A cor, na segunda coluna do Quadro 1 foi definida a partir de uma composição colorida das bandas TM3, TM4 e TM5, associadas respectivamente aos matizes azul, verde e vermelho.

Quadro 2 - Chave de interpretação das classes de interesse.

\begin{tabular}{|c|c|c|c|c|c|}
\hline Classes & $\begin{array}{c}\text { Cor (composição } \\
\text { colorida) }\end{array}$ & Textura & Forma & Figura & Descrição \\
\hline Água & Negro & Lisa & Irregular & & $\begin{array}{c}\text { Áreas cobertas por água: } \\
\text { rios, lagos e reservatórios. }\end{array}$ \\
\hline $\begin{array}{c}\text { Plantas } \\
\text { aquáticas }\end{array}$ & Verde-claro & Lisa & Irregular & & $\begin{array}{c}\text { Áreas com presença de } \\
\text { plantas aquáticas. }\end{array}$ \\
\hline
\end{tabular}

A classificação das imagens do reservatório da UHE de Americana foi feita pelo classificador Bhattacharya, que é um classificador supervisionado por regiões, conforme descrito anteriormente. Inicialmente, foi feito o treinamento do algoritmo de classificação, selecionando-se áreas representativas de cada classe de interesse. Para cada uma das classes pré-definidas foram coletados seus segmentos correspondentes. 


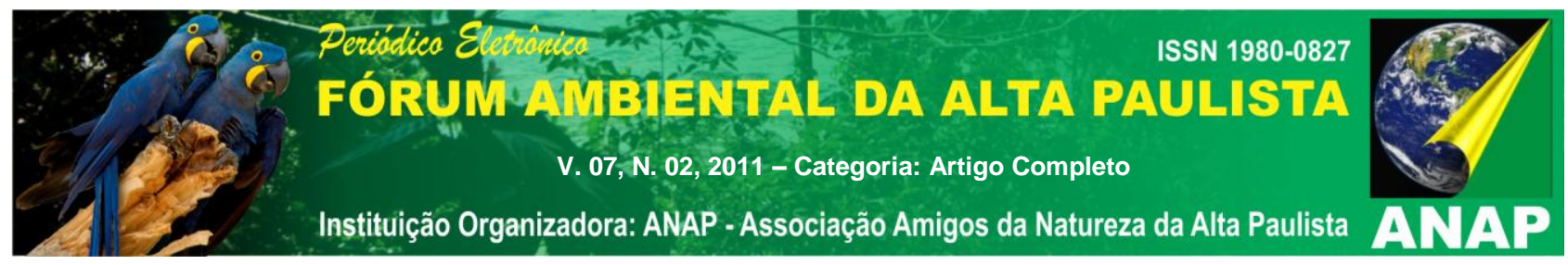

Como resultado, obteve-se imagens classificadas do reservatório para os anos de 2008, 2009 e 2010. Cada uma dessas imagens passou pelo procedimento de mapeamento de classes que gerou mapas temáticos mostrando a distribuição espacial das áreas de infestação por plantas aquáticas, em três momentos no tempo.

\section{5 - RESULTADOS E DISCUSSÕES}

O processo de registro de imagens fornece como um possível indicador da qualidade do ajuste geométrico, uma medida de erro que, a literatura recomenda, seja inferior a um (1) pixel. Para a imagem do ano de 2008 registrada em relação à imagem ETM+/Landsat 7, esse erro foi de 0,742 pixel; para a imagem de 2009, o erro foi de 0,731 pixel; e para a imagem de 2010 de 0,707 pixel.

O procedimento de exclusão da área do entorno do reservatório possibilitou a posterior classificação do corpo d'água quanto a presença de plantas aquáticas, sem que estas se confundissem com outras classes de cobertura do solo, como plantações.

Como resultado do processo de classificação da Represa de Americana, foram obtidos mapas mostrando as áreas de infestação por plantas aquáticas nos anos de 2008, 2009 e 2010. A seguir, as Figuras 5, 6 e 7 mostram o mapa temático resultante da classificação das imagens TM/Landsat 5 tomadas nessas datas. As áreas infestadas por plantas aquáticas são destacadas em verde, enquanto que as demais áreas são destacadas em azul. 

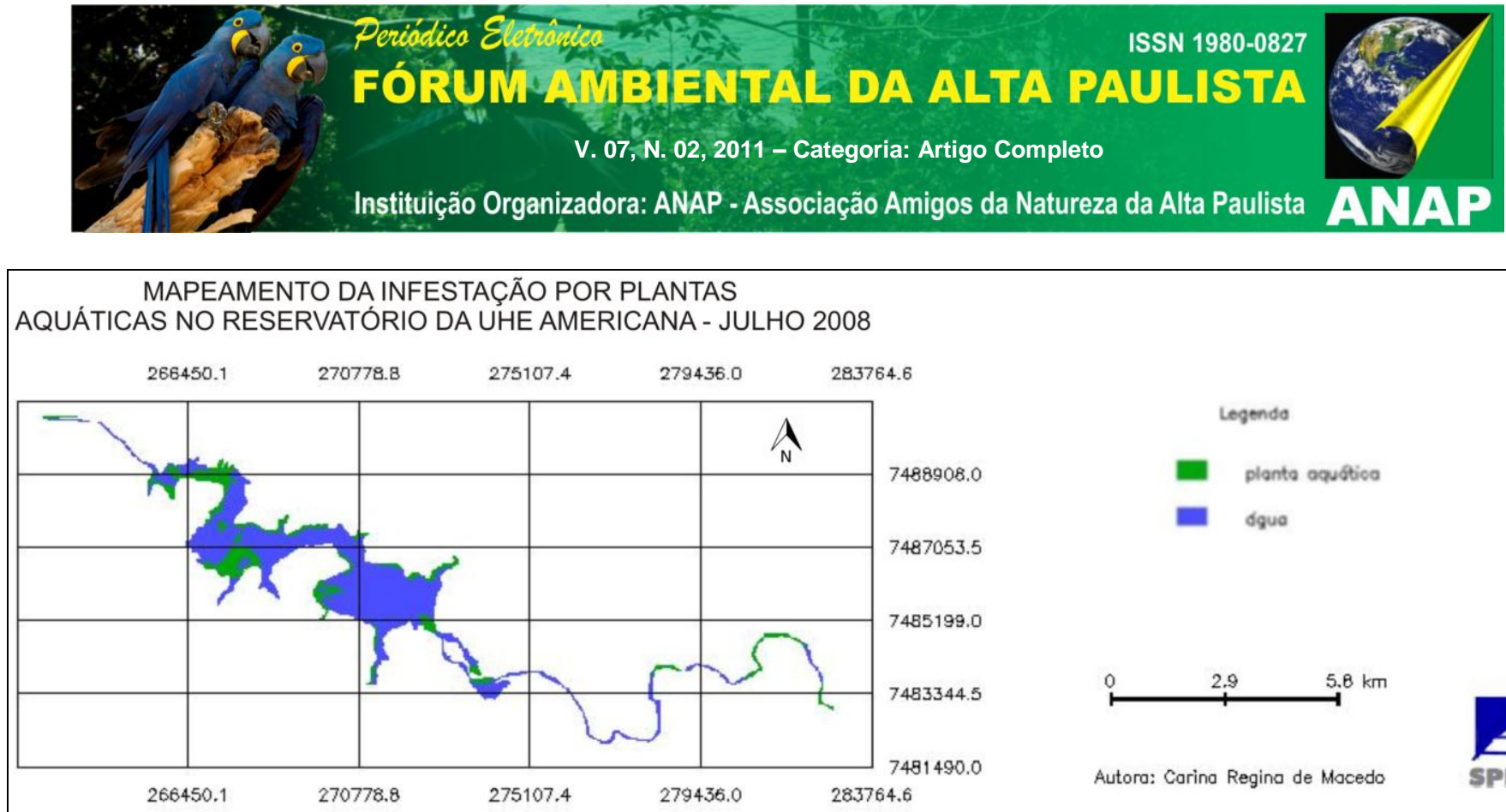

Figura 5 - Mapa da Infestação por plantas aquáticas no Reservatório de Salto Grande no dia 08/07/2008.

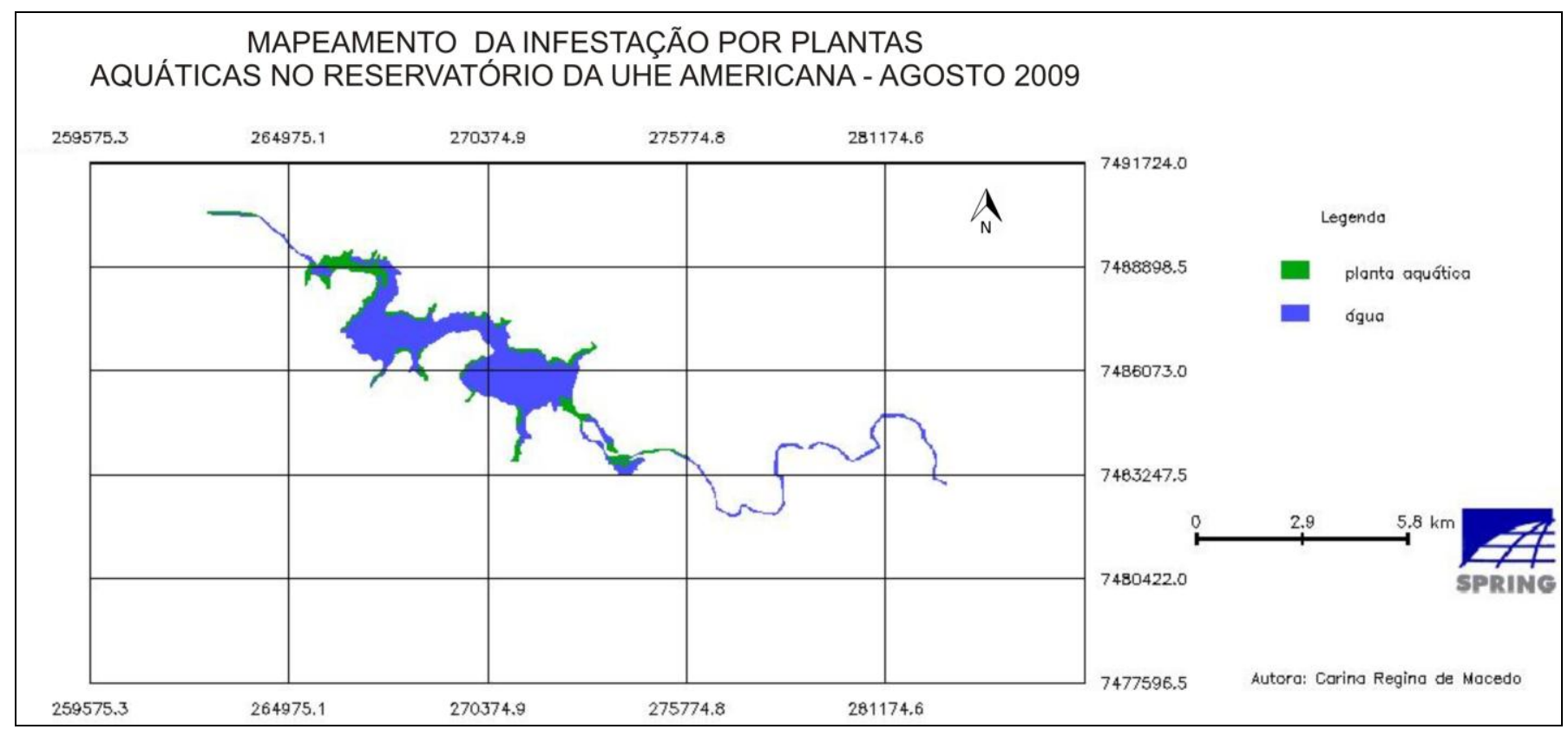

Figura 6 - Mapa da Infestação por plantas aquáticas no Reservatório de Salto Grande no dia 28/08/2009. 

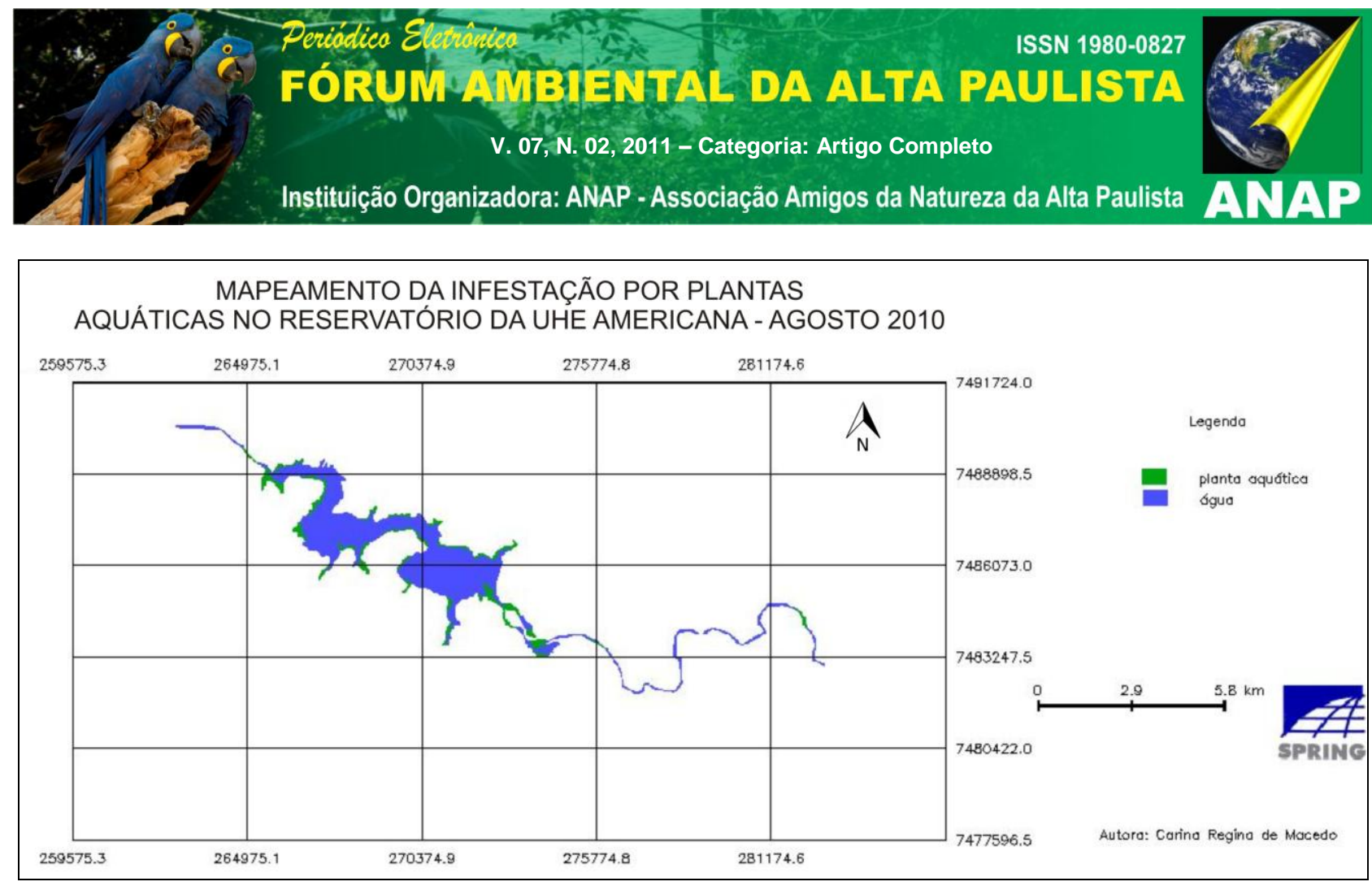

Figura 7 - Mapa da Infestação por plantas aquáticas no Reservatório de Salto Grande no dia 31/08/2010.

Percebe-se, a partir da análise das imagens classificadas, que a infestação por plantas se dá próxima às margens da represa, sendo possível, com esses mapas gerados, localizar áreas nas quais a incidência de plantas é constante em todos os anos estudados. Essas regiões podem apresentar velocidade de corrente reduzida e pouco profundidade, e/ou concentrações elevadas de nitrogênio e fósforo, e/ou sedimentos. No entanto, mais estudos precisam ser realizados a fim de se verificar o motivo da infestação nessas áreas.

Para se fazer uma análise mais adequada das áreas mapeadas com plantas aquáticas, foi feita uma estimativa do percentual da área da Represa de Salto Grande que é infestada por essas plantas. O gráfico 1, que segue, apresenta os resultados dessas quantificações. 

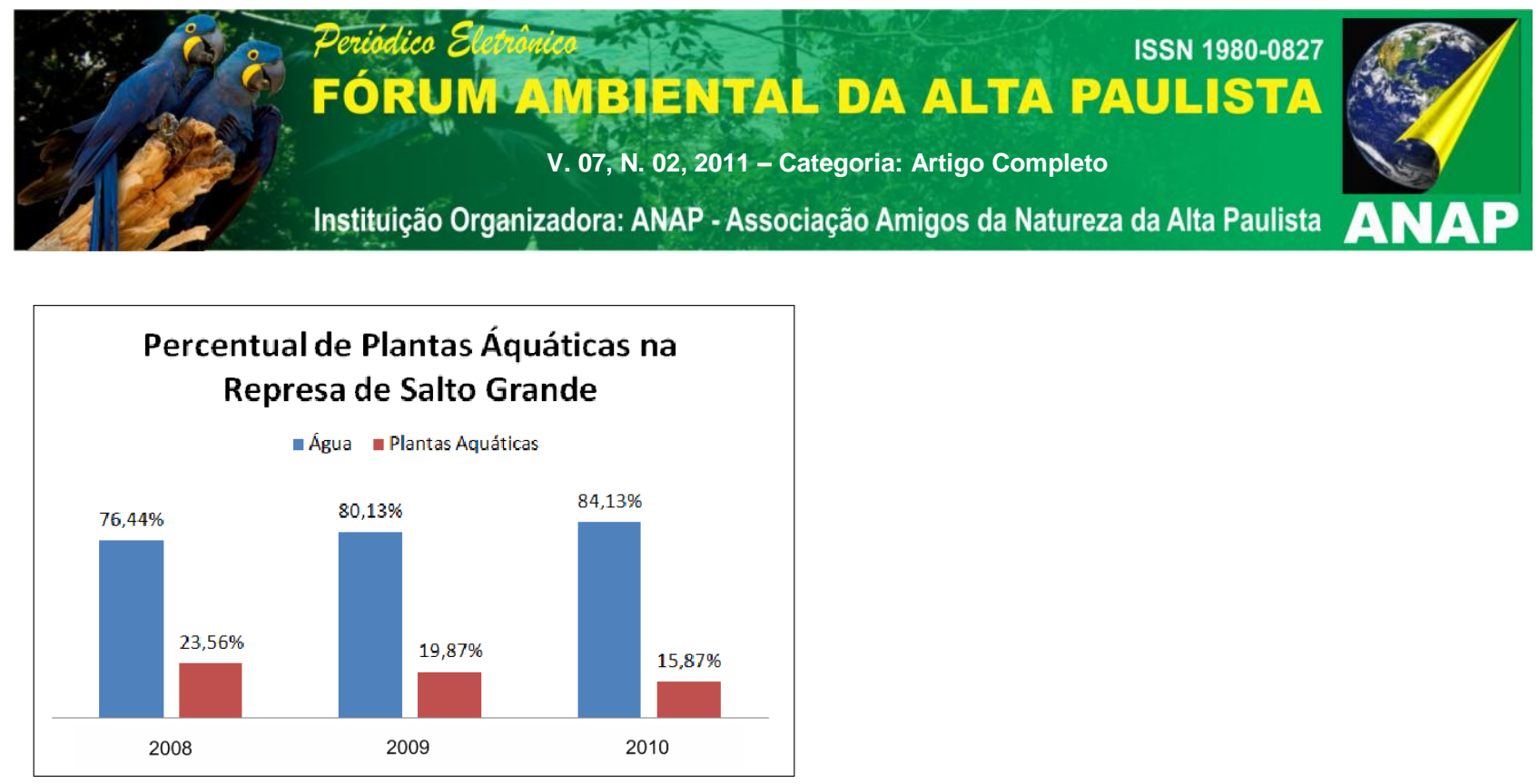

Gráfico 1 - Percentual de Plantas Aquáticas mapeadas no Reservatório de Salto Grande durante os anos de 2008, 2009 e 2010.

A maior extensão de área mapeada com planta aquática corresponde ao ano de 2008, seguido pelo ano de 2009 e, então, como menor extensão, tem-se o ano de 2010. Esses resultados coincidem com o estudo feito por Moraes (2011) nesse mesmo Reservatório, no qual ele constatou que a área mapeada com plantas aquáticas na Represa em 2008 foi maior que a mapeada no ano de 2010, sendo que, no primeiro ano em questão, as áreas cobertas por plantas correspondiam a 33\% e, no segundo ano, a $26 \%$.

A maior extensão de área coberta por plantas aquáticas no reservatório, em 2008, para MORAES (2011, p. 2574) "pode ser resultado de processos de eutrofização mais intensos causados por resíduos em geral lançados na água, ou seja, que a carga de nutrientes e matéria orgânica responsável por sua proliferação tenha sido maior em 2008 do que em 2010".

Outro fator que pode ter influenciado a diferença na extensão da área coberta por plantas aquáticas no reservatório nos três anos considerados desse estudo, é a retirada periódica das macrófitas ao longo do reservatório, já que esta ação influencia na quantidade de plantas detectadas nas imagens. É importante levar em consideração a data das imagens utilizadas, pois imagens de diferentes períodos do ano podem apresentar diferenças geradas pela sazonalidade, porém nesse estudo, pelo fato das imagens serem de próximas épocas do ano, esse fator não deve ser de extrema relevância. 


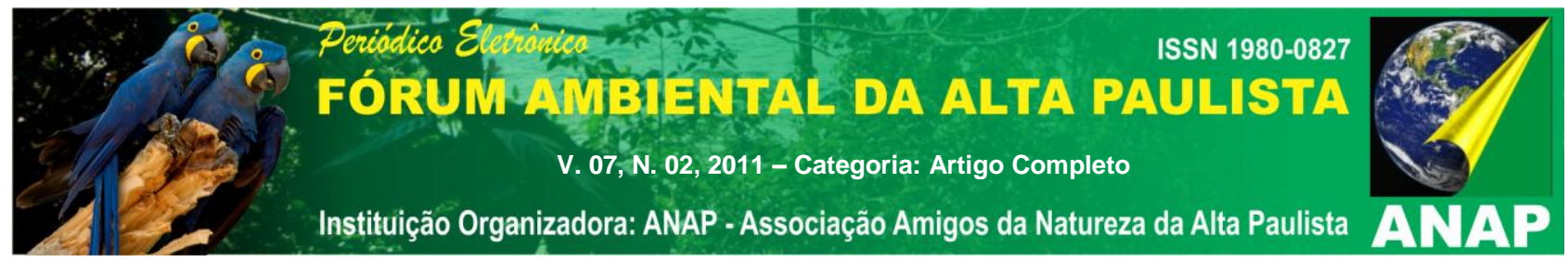

\section{6 - CONCLUSÃO}

Conforme indicam os resultados obtidos, foi possível realizar o monitoramento da ocorrência, em termos quantitativos e de distribuição espacial, de plantas aquáticas no reservatório de Salto Grande, assim como comparar a situação encontrada nessa área nos três anos em estudo (2008, 2009 e 2010). A distribuição das áreas cobertas por plantas se concentrou nas margens da represa; e o estudo desenvolvido mostrou que houve variação na área infestada por plantas aquáticas entre os anos estudados, sendo que foi possível perceber a diminuição da área mapeada com plantas aquáticas no decorrer desses anos.

A utilização de imagens multiespectrais TM/Landsat 5 e ETM ${ }^{+} /$Landsat 7 foi satisfatória para se chegar ao objetivo do trabalho que ora se apresenta, já que estas possuem características que deixam uma vantajosa relação custo-benefício para o usuário, como: distribuição gratuita, boa resolução espectral, espacial e temporal.

Dessa maneira, pelo fato das plantas aquáticas influenciarem muito as atividades humanas e os processos físicos e químicos encontrados em um ecossistema, a quantificação das áreas infestadas por estas plantas podem fornecer informações que podem contribuir para a elaboração do plano de manejo do reservatório em questão, já que os mapas gerados nesse trabalho podem ajudar no acompanhamento das mudanças espaciais e temporais das áreas infestadas.

AGRADECIMENTOS: A Universidade Estadual "Júlio de Mesquita Filho", Faculdade de Ciência e Tecnologia, campus de Presidente Prudente pela possibilidade de formação, a CNPQ/PIBITI pelo aporte financeiro e ao Luciano Francisco de Oliveira e a Carla Eloísa Diniz dos Santos pela ajuda prestada.

\section{BIBLIOGRAFIA}

CPFL - Companhia Piratininga de Força e Luz. (2010). Quantidade de Plantas Aquáticas Coletadas na UHE Americana. 


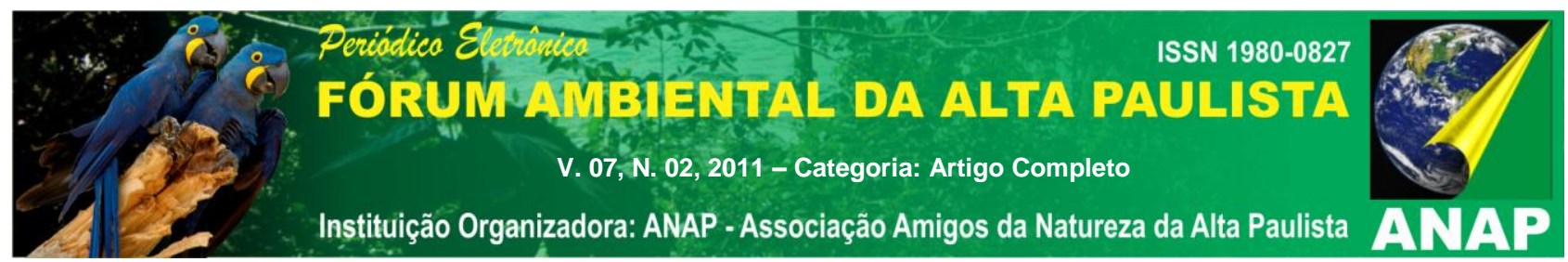

CPFL - Companhia Piratininga de Força e Luz (2008). Controle de Plantas Aquáticas no Reservatório da UHE Americana. Disponível em: <http://www.comitepcj.sp.gov.br/download/CT-SAM_Plantas-Aquaticas-UHEAmericana.pdf>. Acesso em: 08 out. 2010.

CRUZ, N.C. (2005). Uma análise da infestação por plantas aquáticas utilizando imagens multiescala e redes neurais artificiais. Dissertação (Mestrado em Ciências Cartográficas) Faculdade de Ciências e tecnologia, Universidade Estadual Paulista, Presidente Prudente - SP, $99 f$.

CRUZ, N.C.; GALO, M.L.B.T. (2005). Mapeamento das infestações por plantas aquáticas em Reservatórios utilizando imagens multiescala e redes neurais artificiais. Rev. Brasileira de Cartografia. Rio de Janeiro - RJ, v. 57. Disponível em: <http://www.rbc.ufrj.br/_pdf_57_2005/57_2_06.pdf>. Acesso em: 1 jun. 2011

EMBRAPA. (2010). Landsat 7 - Landsat Remote Sensing Satellite. Disponível em: <http://www.sat.cnpm.embrapa.br/conteudo/landsat.htm>. Acesso em: 03 mar. 2011.

FLORENZANO, T. G. (2002). Imagens de satélite para estudos ambientais. Oficina de Textos São Paulo - SP, 97 p.

GALO, M.L.B.T. (2002). Uso do sensoriamento remoto orbital no monitoramento da dispersão de macrófitas nos reservatórios do complexo Tietê. Rev. Planta Daninha. Viçosa - MG, v. 20. Disponível em: <http://www.scielo.br/scielo.php?pid=S010083582002000400002\&script=sci_arttext>. Acesso em: 09 nov. 2010.

INPE - INSTITUTO NACIONAL DE PESQUISAS ESPACIAIS. (2011). Classificação de Imagens. Disponível em: <http://www.dpi.inpe.br/spring/portugues/tutorial/classific.html>. Acesso em: 10 fev. 2011.

JENSEN, J. R. (2009). Sensoriamento remoto do ambiente: uma perspectiva em recursos terrestres. Tradução José Carlos Neves Epiphanio (coordenador)... et al. Parêntese São José dos Campos - SP, 598 p.

KÖRTING, T. S. (2006). Classificação de imagens por regiões. São José dos Campos SP, 10 p. Disponível em: <http://www.dpi.inpe.br/ tkorting/projects/isoseg/material.pdf>. Acesso em: 4 mai. 2011.

MORAES, D.A.C.; SARTORI, A. A. C.; NOSSACK, F. A.; SPADOTTO, C. A., ZIMBACK, C. R. L. (2011). "Estimativa e comparação da área ocupada por plantas aquáticas na superfície da Represa Salto Grande - SP com auxílio da classificação de imagens CBERS-2B" in Anais do XV Simpósio Brasileiro de Sensoriamento Remoto, Curitiba, abr. 2011, pp. 2569 - 2575. Disponível em: <http://www.dsr.inpe.br/sbsr2011/files/p0568.pdf>. Acesso em: 13 jun. 2011.

MOREIRA, M. A. (2001). Fundamentos do Sensoriamento Remoto e Metodologias de Aplicações. 


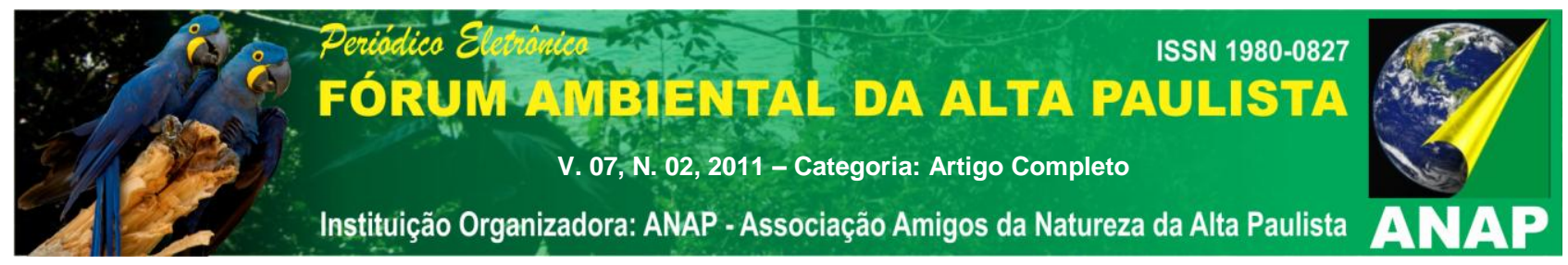

São José dos Campos - SP, INPE, 250 p.

NOVO, E.M.L.M. (1992). Sensoriamento Remoto: princípios e aplicações. 2. Ed. Editora Edgar Blücher São Paulo - SP, 308 p.

SANTOS, A.R.; PELUZIO, T.M.O; SAITO, N.S. (2010). SPRING 5.1 .2 passo a passo: aplicações práticas. 1. ed. Programa de Pós-Graduação em Ciências Florestais da UFES Alegre - ES, $153 \mathrm{p}$.

TRENTIN, A.B. (2009). Sensoriamento Remoto Aplicado ao Estudo do Comportamento Espectral da Água no Reservatório Passo Real - RS. Dissertação (Mestrado em Geografia) - Universidade Federal de Santa Maria, Santa Maria - RS, 97 f. Disponível em:

$<$ http://w3.ufsm.br/ppggeo/index2.php?option=com_docman\&task=doc_view\&gid=81\&lte mid=30>. Acesso em: 10 nov. 2010.

VENTURIERI, A.; SANTOS, J.R. "Técnicas de Classificação de Imagens para Análise de Cobertura Vegetal". In Sistema de Informações Geográficas: Aplicações na Agricultura. Org por ASSAD, E.D.; SANO, E.E. 2. ed. Serviço de Produção de Informação Brasília -DF, 434 p.

(2010). Landsat 5 TM - Ficha Técnica Resumida. Disponível em: <http://www2.engesat.com.br/?system=news\&action=read\&id=528>. Acesso em: 03 mar. 2011.

. (2010). Landsat $7 E^{+} M^{+}$- Ficha Técnica Resumida. Disponível em: <http://www.engesat.com.br/?system=news\&action=read\&id=526\&eid=308>. Acesso em:0 3 mar. 2011.

(2010). Catálogo de Imagens. Disponível em: <http://www.dgi.inpe.br/CDSR/>. Acesso em: 23 ago. 2010.

Spring.

Disponível

em:

$\overline{<h t t p: / / w w w . d p i . i n p e . b r / s p r i n g / p o r t u g u e s / i n d e x . h t m l>. ~ A c e s s o ~ e m: ~} 15$ jul. 2010. 